\title{
PerCursos
}

\section{Inventar el cine: sobre técnicas e estéticas de documentários latino-americanos}

\begin{abstract}
Resumo
Este artigo expõe e discute as diferentes formas pelas quais o cinema documentário latino-americano buscou traduzir os dilemas sociais do continente. A partir da análise de filmes realizados no continente nos últos 60 anos, abordamos algumas das principais escolas e modos de fazer documentário, como os modelos inglês e sociológico, o terceiro cinema, o documentário em primeira pessoa e o filme-ensaio. Buscamos apontar as origens das distintas abordagens (tanto cinematográfica quanto social) nos distintos contextos sociais, circunstâncias históricas e em novas possibilidades de deslocamento e registro propiciadas pelo advento de novas tecnologias.
\end{abstract}

Palavras-chave: documentário latino-americano; cine nuevo latinoamericano; filme ensaio; Eduardo Coutinho; Patricio Guzmán.

\author{
Daniel Velasco Leão \\ Doutor em Artes Visuais pela \\ Universidade do Estado de Santa \\ Catarina - UDESC com período \\ sanduíche na New York \\ University. Diretor Formativo \\ Cinemateca Catarinense ABD/SC. \\ Brasil \\ leao@tutanota.com \\ orcid.org/0000-0001-9957-6779
}

\footnotetext{
Para citar este artigo:

LEÃO, Daniel Velasco. Inventar el cine: sobre técnicas e estéticas de documentários latino-americanos.

PerCursos, Florianópolis, v. 22, n.50, p. 270 - 291, set./dez. 2021.
}

DOI: $10.5965 / 1984724622502021270$

http://dx.doi.org/10.5965/1984724622502021270 


\title{
Inventar el cine: on techniques and aesthetics of latin american documentaries
}

\begin{abstract}
This essay addresses the different ways in which Latin American documentary cinema has sought to translate the continent's social dilemmas. Through films made on the continent in the last 60 years, we approach some of the main schools and ways of making documentaries, such as the expository documentary, the Brazilian sociological model, the third cinema, the subjective turn and the film essay. We seek to point out the origins of the different strategies (both cinematographic and social) in dissimilar social settings, historical circumstances, and the new possibilities of displacement and registration provided by the advent of new technologies.
\end{abstract}

Keywords: latin american documentary; cine nuevo latinoamericano; essay film; Eduardo Coutinho; Patricio Guzmán. 


\section{Introdução}

Raramente um filme documentário deixa de abordar aspectos críticos das sociedades em que é realizado. A forma assertiva, e eventualmente reflexiva, de se reportar à realidade contribuiu de forma considerável para a constituição do cinema documentário como um campo distinto de cinematografia e para sua institucionalização social. A rigor, mesmo o modo como nos referimos ao conjunto heterogêneo de filmes que compõem este campo o indica: Documentário. O termo foi utilizado pelo escocês John Grierson com o intuito de lhe conferir legitimidade junto à burocracia britânica que queria convencer a financiar um departamento dedicado a realizá-los, o que de fato acaba ocorrendo (DA-RIN, 2006). Em língua inglesa, o termo documentary data de 1802 e tem por acepção principal "Of the nature of or consisting in documents" (Oxford English Dictionary). Em português, a primeira ocorrência registrada da palavra data de 1913 e, provavelmente, tem origem inglesa. Termo infeliz que desde os primeiros anos até hoje segue gerando controvérsia, incômodo e, eventualmente, revolta.

O movimento documentário britânico acabaria constituindo um modelo de filme documentário que viria a ser seguido e contestado ao longo da (breve) história do cinema. Seus objetivos pedagógicos essenciais foram compartilhados por boa parte dos documentaristas latino-americanos de meados do século 20 até que o engajamento mais direto dos cineastas na luta anti-ditatorial e/ou revolucionária alterasse senão o desejo de transmitir um conhecimento, seu modo de fazê-lo. A partir daí, passam a conviver dois grupos de filmes, aos quais logo se somam outros: filmes com o objetivo de escuta da experiência/conhecimento do outro; filmes que buscam a auto-expressão subjetiva; filmes que se valem de diversos desses objetivos que, eventualmente, são realizados como ensaios. Cada um desses grupos é formado por filmes heterogêneos e sua sucessão não é absoluta: hoje encontramos documentários realizados com objetivos educativos, de transformação da sociedade, de escuta, de autoexpressão etc. Este artigo realiza o mapeamento histórico dessas variações, relacionando-as tanto às mudanças sociais e às novas possibilidades expressivas e reflexivas decorrentes das transformações nos equipamentos utilizados por documentaristas. 
A produção documentária de Humberto Mauro exemplifica os objetivos pedagógicos que acabaram por dominar a escola britânica. Durante o período em que trabalhou no Instituto Nacional do Cinema Educativo (1937-1964), Mauro realizou mais de 300 filmes. Ainda que nessa vasta produção existam filmes-invenção, como Alberto Nepomuceno (1950), em que não vemos na tela senão nuvens, a maior parte dela se baseia na transmissão de conhecimentos. Deve-se dizer, no entanto, que isso decorre do que Getúlio Vargas - em cuja ditadura seria fundado o INCE — pensava ser a utilidade e a função do cinema. No discurso O cinema nacional, elemento de aproximação dos habitantes do país, realizado um 1936, Getúlio afirma: “Elemento de cultura influindo diretamente sobre o raciocínio e a imaginação, ele [o cinema] apura as qualidades de observação, aumenta os cabedais científicos e divulga o conhecimento das coisas, sem exigir esforço e as reservas de erudição que o livro requer e os mestres, nas suas aulas, reclamam" (VARGAS, 1934, apud AUTRAN, 2013, p. 116-117). Adiante, afirma que o cinema “aproximará pela visão incisiva dos fatos, os diferentes núcleos humanos, dispersos no território vasto da República" (VARGAS, 1934, apud AUTRAN, 2013, p. 117).

\section{$\mathrm{O}(\mathrm{s})$ documentário(s) do nuevo cine latinoamericano}

Apenas o engajamento político dos cineastas nos anos 1950-1970 irá alterar a paisagem documental. Há um período de transição em que o objetivo segue sendo informar, porém informar não mais sobre como os Joões-de-barro constróem suas casas: a denúncia social marca a produção do primeiro período do chamado Cine Nuevo Latinoamericano. Tire dié, de Fernando Birri (1960), com notável influência do neorrealismo italiano, denuncia o subdesenvolvimento e a desnutrição de crianças que correm ao lado de um trilho de trem pedindo que os passageiros atirem moedas de dez

\footnotetext{
${ }^{1}$ Mesmo dentro desses pressupostos, Humberto Mauro realiza projetos de notável qualidade técnica e estética, como a série Brasilianas, em que não apenas "ritmo, paisagem natural e sons são elementos indissociáveis" (SCHWARZMAN, 2004, p. 273), como se percebe ainda trabalhos inteiramente singulares, como Alberto Nepomuceno (1950) em que vemos apenas nuvens. Dez desses filmes foram realizados entre 1945 e 1964 (o último, o popular A velha a fiar), mas um deles foi realizado dez anos depois: Carro de bois. Quanto à prodigiosa produção de Humberto Mauro, há que se mencionar ainda, que um ano antes da Sinfonia de São Paulo, Mauro realizara em sua cidade Sinfonia de Cataguases, filme lamentavelmente perdido.
} 
centavos. Para seu diretor, que funda uma escola de cinema em Santa Fé, a função revolucionária - do documentário era testemunhar a realidade, denunciá-la, desmontála. Em Cine y subdesarrollo, texto escrito dois anos depois do filme, Birri pergunta-se qual cinema é necessário para a Argentina e para os povos subdesenvolvidos da América Latina. Ele mesmo responde:

\begin{abstract}
Um cinema que os desenvolve. Um cinema que lhes dê consciência; esclareça-os; que fortaleça a consciência revolucionária de quem já a possui; que os fervilhe; que perturbe, preocupe, amedronte, enfraqueça, quem tem "consciência pesada", consciência reacionária; que defina perfis nacionais e latino-americanos; que o torne autêntico; que seja antioligárquico e anti-burguês na ordem nacional e anti-colonial e antiimperialista na ordem internacional; que seja pró-povo e contra o antipovo; que ajude a emergir do subdesenvolvimento para o desenvolvimento, do sub-estômago para o estômago, da subcultura para a cultura, da sub-felicidade para a felicidade, da sub-vida para a vida. Estamos interessados em fazer um novo homem, uma nova sociedade, uma nova história e, portanto, uma nova arte, um novo cinema. Urgentemente. (BIRRI, 1988, p. 12)
\end{abstract}

Para tal, parecia suficiente colocar-se diante da realidade e filmá-la: "O que eu queria era descobrir o rosto de uma Argentina invisível — invisível não porque não se a via, mas porque não se queria vê-la", afirma Birri (BIRRI, 1979 apud AVELLAR, 1995, p. 60).

No Brasil foram realizados, no mesmo período, Aruanda, de Lindoarte Noronha (1960) e Arraial do Cabo, de Mário Carneiro e Paulo César Saraceni (1959). Arraial do cabo narra as transformações sociais decorrentes da instalação da Fábrica Nacional de Álcalis em Cabo Frio, causando a morte dos peixes e outras alterações danosas aos modos de vida dos pescadores do então vilarejo Arraial do Cabo. Já Aruanda narra o cotidiano e o trabalho de remanescentes de um quilombo situado na Serra do Talhado, Paraíba².

\footnotetext{
${ }^{2}$ Esses dois curtas documentários foram referências fundamentais para a estética do Cinema Novo. Glauber Rocha chegou a referir-se ao filme de Lindoarte Noronha como uma "revolução brutal" (ROCHA, 2004, p. 147). Aqui, o povo era "retratado sempre em alteridade radical, mas em um patamar menos elevado, menos idealizado, menos folclorizado, que a representação do popular encontrada até então" (RAMOS, 2008, p. 326-327).
} 
Maioria absoluta, de Leon Hirszman (1964), tem a mesma inclinação: composto pela combinação de entrevistas captadas com som direto com analfabetos e por uma narração desengajada (em voz over). Mas há em Maioria um desejo de confronto com o espectador ausente dos filmes anteriores. Pode-se percebê-lo nas palavras finais do narrador: "O filme acaba aqui. Lá fora, a tua vida, como a destes homens, continua". Como observa Bernardet, desse modo, o filme "nos incita a uma ação que transforme essa situação que, agora, espectadores do filme, não teremos mais desculpas para ignorar. Não agir seria cumplicidade com esse estado de coisas. O filme pretende ter uma ação transformadora sobre nós: ele nos informou, espera de nós a ação consequente" (BERNARDET, 2003, p. 41-42).

O contato com o espectador é levado adiante por Fernando Solanas e Octavio Getino, em filme dividido em três partes que somam mais de quatro horas: La hora de los hornos (1968). O filme, realizado sob o impacto da morte de Ernesto Che Guevara, é, para Guy Gauthier, "uma das primeiras formulações da teoria de intervenção do cinema" (GAUTHIER, 2011, p. 211). Em um manifesto célebre, Hacia un tercer cine, lançado junto com o filme, elaboram as bases de um cinema que, contrapondo-se tanto ao cinema hollywoodiano quanto ao cinema de autor ${ }^{3}$, que, para não chegar apenas aos intelectuais mas também aos setores mais envolvidos da luta anticolonial, deveria criar novas formas e estratégias para a "produção, difusão e possibilidades econômicas de sobrevivência" do cine-guerrilha (GETINO; SOLANAS, 1988, p. 39). Direcionado aos militantes políticos, La hora de los hornos é composto por pausas e interrupções destinadas à discussão dos temas pelos próprios espectadores: o objetivo, lemos em Hacia un tercer cine, é que se abrisse“ em cada projeção, como em uma incursão militar revolucionária, um espaço liberado, um território descolonizado", cada sessão teria o potencial de se tornar um ato político ou, nas palavras de Franz Fanon, “um ato litúrgico, uma ocasião privilegiada que

\footnotetext{
${ }^{3} \mathrm{O}$ cinema de autor, que contrapunha-se ao cinema industrial hollywoodiano, era reconhecido como importante antecessor que além de reivindicar "a liberdade do autor de se expressar de forma não padronizada, como uma abertura ou tentativa de descolonização cultural", começara a "gerar suas próprias estruturas: formas de distribuição e seus próprios canais de exibição (principalmente cineclubes ou cinemas de arte, etc.), além de ideólogos, críticos e revistas especializadas" (GETINO; SOLANAS, 1988, p. 32).
} 
tem o homem para ouvir e dizer" (FANON, 1961 apud GETINO; SOLANAS, 1988, p. 45) ${ }^{4}$. A busca de Solanas e Getino é partilhada pelo também argentino Grupo Cine da la Base, do qual fazia parte o cineasta Raymundo Gleyzer até ser assassinado/desaparecido pela ditadura militar argentina em 1976.

Tais aspectos também reverberam no boliviano Jorge Sanjínes ${ }^{5}$ e no grupo Ukamau. Mas, diferente dos seus pares argentinos que desejam se direcionar a grupos já organizados, ao rejeitar como público "a elite intelectual, os estudantes da cidade, a classe média" (SANJÍNES, 1988, p. 75), o Ukamau busca não os grupos já organizados e sim a maioria da população boliviana: "é a maioria que deve libertar-se" (idem). Com um público distinto, muda-se o tema e o modo de fazer filmes. "Podemos contar às pessoas sobre sua própria dor? Não. O povo sabe mais da fome que ele passa, do frio que passa, do que nós cineastas, então esses filmes para o povo... significam pouco" (SANJíNES, 1988$, p. 76$)^{6}$. Logo o grupo Ukamau passaria a realizar filmes junto ao povo a que se destinam, considerando-se um "veículo" para que o povo expresse sua história. Assim, em El enemigo principal de 1974, elaboram uma estética depreendida da cosmovisão do povo Quechua, incluindo a antecipação do desfecho, o herói coletivo e o abandono da decupagem clássica (em especial o primeiro plano) em favor de formas que denotassem diferentes maneiras de relação com a comunidade e a natureza, da qual se percebem como parte e não como senhores ou seres distintos. Os planos mais longos buscavam

\footnotetext{
${ }^{4}$ A primeira parte se constitui como um agitprop ensaísta que se vale do uso de cartelas, narrações irônicas, a montagem de material de diversas origens (como imagens de arquivo, Tiré dié! e Maioria Absoluta) com influência de Vertov e de Santiago Álvarez, especialmente Now! (1965). A segunda, um filme aberto aos estudante e sindicalistas, que Guy Gauthier descreveu como exemplo de "aplicação sem concessões das técnicas do cinema direto até então reservado a alguns países privilegiados" (2011, p. 235) com grande influência sobre o cinema militante.

${ }^{5}$ Apesar de se notabilizar por filmes ficcionais, Sanjínes é passível de ser considerado documentarista na tradição de Flaherty e Rouquier e ilustra o "impulso que o documentário dá ao cinema ficcional latinoamericano" (CHANAN, 2013, p. 526).

${ }^{6}$ Também García Espinosa, documentarista cubano, expressa-se de modo semelhante: "Um cinema que se dedica a refletir precisamente a imagem do povo, a miséria do povo, é um cinema quase sempre dedicado à pequena burguesia para que tome consciência da realidade do povo. Um cinema como este nunca será um verdadeiro cinema para as pessoas que já as conhecem, que já experimentam estas imagens em primeira mão e que, por isso, na maioria das vezes as aborrecem. Um cinema para o povo não é aquele que apenas devolve a sua imagem, mas que, acima de tudo, oferece a possibilidade de a superar. Mas, além disso, deve-se ter em mente que existem diferentes formas de fazer filmes. Tem a reportagem, o cinema didático, o filme-ensaio, o cinema recriação etc. Tudo igualmente importante se partirmos do fato de que o que nos interessa é se ele responde ou não a uma verdadeira necessidade cultural" (ESPINOSA, 1988, p. 77).
} 
expressar a integridade coletiva do povo entre si e com a natureza. Em entrevista recente, Sanjínes afirma: “o cinema que pretendia atingir o maior número de espectadores bolivianos deveria ser construído sob os preceitos inspirados nos mecanismos internos de outra visão de mundo, a visão majoritária, a visão das culturas indígenas" (SANJÍNES; BESKOW, 2016, p. 25).

José Carlos Avellar observa que seria impossível avaliar essas produções sem notar como tudo o que aconteceu nos países subdesenvolvidos em meados do século as influenciou:

o cinema latino-americano que surge neste momento é uma expressão da mesma vontade/sonho/desejo/decisão que levou à Revolução Cubana, à luta contra o colonialismo na Argélia, em Angola, em Moçambique, no Vietname; [...] é expressão de outras vontades de se descolonizar culturalmente que ocorreram aqui mesmo e que foram sufocadas por seguidos golpes de Estado e ditaduras militares. Nosso cinema, entre 1954 e 1964, surge com uma expressão da vontade de se liberar que toma conta das culturas oprimidas pelo colonialismo na América Latina, na África, na Ásia; vontade de que pouco depois, em torno de maio de 68 , se estendeu até a Europa [...] apanhada de surpresa pelo cinema e música, e literatura, e tudo o mais que gritava contra o colonialismo. (AVELLAR, 1995, p. 118)

Paulo Paranaguá aponta ainda outros dois elementos centrais para o surgimento deste cinema. Primeiro, o advento em finais da década de 1950 do grupo sincrônico ligeiro, isto é, câmeras e gravadores leves, sincronizáveis, e passíveis de serem transportados sem muitas dificuldades ${ }^{7}$. Depois, mas não menos importante, a mudança no perfil dos cineastas que passam agora a serem jovens intelectuais que compartilham com os

\footnotetext{
${ }^{7}$ Denominação de Mario Ruspoli às câmeras leves e silenciosas, películas sensíveis a condições de luz mais baixas, gravadores magnéticos portáteis e sincrônicos que tornaram-se disponíveis no final da década de 1950 (DA-RIN, 2006). Esses equipamentos facilitaram o registro em som direto fora dos estúdios, que já havia sido realizado, entretanto, em filmes pioneiros como Housing Problems (Arthur Elton, Edgar Anstey, John Taylor e Ruby Grierson, 1935) e em experimentos de Dziga Vertov. Assim como na América Latina, tal advento foi responsável por diversas rupturas e novas formas de fazer cinema na Europa e nos Estados Unidos. Entre nós, o "advento" do grupo sincrônico ligeiro deve ser relativizado. Em Carlos: Cineretrato de un caminante de 1965, ainda sem dispor de gravadores, o uruguaio Mario Handler se vale de um recurso utilizado por Jean Rouch, destacado representante do cinéma véritè francês, quase uma década antes, combinando imagens da vida de seu personagem andarilho com o áudio gravado pelo personagem central em um estúdio.
} 
autores literários a busca por uma linguagem autenticamente nacional e, eventualmente, latino-americana.

Grande parte do documentário brasileiro realizado depois de Aruanda e Arraial do Cabo, incluindo Maioria absoluta, configura-se no que Bernardet denominou filme sociológico. Esse modelo se caracteriza pelo recurso a narradores em voz over e de entrevistas com pessoas em situação de precariedade. Na estrutura do filme, estes servem "como uma amostragem que exemplifica a fala do locutor e que atesta que seu discurso é baseado no real [... ] os migrantes - de que os entrevistados são a amostragem - são o objeto da fala do locutor, que se constitui sujeito detentor do saber" (BERNARDET, 2003, pp. 17-18).

Para que o sistema [de amostragem] funcione, é necessário que se limpe o real de maneira a adequá-lo ao aparelho conceitual. É essa limpeza que permite o funcionamento básico de produção de significação do filme: a relação particular/geral. O filme funciona porque é capaz de fornecer uma informação que não diz respeito apenas àqueles indivíduos que vemos na tela, nem a uma quantidade muito maior deles, mas a uma classe de indivíduos e a um fenômeno. Para isso, para que passemos do conjunto das histórias individuais à classe e ao fenômeno, é preciso que os casos particulares apresentados contenham os elementos necessários para a generalização, e apenas eles. [...] essa limpeza do real condicionada pela fala da ciência permite que o geral expresse o particular, que o particular sustente o gera, que o geral saia de sua abstração e se encarne, ou melhor, seja ilustrado por uma vivência. (BERNARDET, 2003, p. 19)

Já nos anos 1970, diversas obras rompem com esse modelo. As características destas obras são: “deixar de acreditar no cinema documentário como reprodução do real, tomá-lo como discurso e exacerbá-lo enquanto tal; quebrar o fluxo da montagem audiovisual e desenvolver uma linguagem baseada no fragmento e na justaposição; oporse à univocidade e trabalhar sobre a ambiguidade" (BERNARDET, 2003, p. 217). Um desses filmes é Jardim Nova Bahia (1971) no qual Aloysio Raulino entrega sua câmera à Deutrudes Carlos da Rocha, um lavador de carros analfabeto. É ele que, portando a câmera e a palavra, nos guia pelo filme. A busca efetiva pelo outro, a subjetividade da câmera-Eu e as obras realizadas por pessoas e comunidades que, até então, vinham 
sendo objetos do documentário, conjugadas neste filme, darão origem a três formas de fazer cinema nas décadas subsequentes.

\section{O documentário ambíguo e frágil}

Cabra Marcado Para morrer, de Eduardo Coutinho (1984), é emblemático do primeiro grupo. A obra é a história do reencontro, vinte anos depois, com os personagens de um filme interrompido em 1964. Realizado dentro do escopo ideológico dos Centros de Cultura Popular (CPC) da UNE, contava a história do líder camponês João Pedro Teixeira, assassinado a mando dos latifundiários da região (numa história evocada em Torto Arado). O filme, interrompido pelo Golpe Militar, era realizado dentro por nãoatores e por pessoas desempenhando seu próprio papel, caso de Elizabeth Teixeira, viúva do líder camponês. Em seu reencontro com as personagens, Coutinho abre o cinema à subjetividade do outro, ao seu próprio discurso, potencializa a dramaturgia natural ao privilegiar os planos longos, o desejo de uma escuta (mais do que de uma fala), valendose do que João Moreira Salles chamou de "um franciscanismo cinematográfico" (SALLES, 2004, p. 8) e de estratégias autorreflexivas. Coutinho encampa, de certo modo, um sentimento comum daquele período, como se percebe nesta fala de Birri em 1985:

Há vários anos o meu irmão Nelson Pereira dos Santos disse-me: "até agora usamos o cinema para ensinar, vamos usar agora para aprender", do barro ao ouro, da "estética da fome" à fome de uma estética subversiva, do fotograma à vida, esta é a grande arte em cuja fornalha estamos queimando. "Que nenhum espectador saia do mesmo jeito depois de terminar de assistir a um de nossos filmes", dizíamos há mais de um quarto de século, exigindo a conscientização de um espectador ativo. "Que nenhum cineasta latino-americano é o mesmo que começou a fazer o filme quando acabou", dizemos hoje. (BIRRI, 1988b, p. 73)

Ao longo das três décadas seguintes, Coutinho iria se dedicar sobretudo

a reunir um conjunto de histórias fragilíssimas, oferecendo a cada uma delas aquilo que, em outros filmes e outras circunstâncias, elas não 
teriam: proteção. Nada mais frágil do que palavras ditas por quem não costuma ser escutado. Elas são bens perecíveis por definição, coisas sem luz de eternidade, na expressão de Simone Weil. O cinema de Coutinho pode ser percebido como uma tentativa bem-sucedida de não permitir que elas desapareçam. (SALLES, 2004, p. 7)

Para a realização dessa cinematografia foi fundamental o recurso ao vídeo já que os chassis de câmeras $16 \mathrm{~mm}$, geralmente utilizadas por documentaristas, duravam entre 3 e 11 minutos. Além dos altos custos do material e de sua revelação, isso gerava a necessidade de frequentes interrupções durante a filmagem o que seria especialmente danoso para uma entrevista dessa natureza. Assim, "por sobrevivência, intuição, sentido de realidade, adequação ao tipo de documentário que queria fazer", nos conta Consuelo Lins, Coutinho opta "por uma prática de documentário em vídeo que se tornaria dominante só a partir do final dos anos 90. Opta, na verdade, por um cinema possível” (LINS, 2006, p. 60).

\section{O documentário subjetivo}

De fato, o vídeo é um dos três fatores determinantes, segundo Pedro Piedras (2016), para o surgimento do móvel documentário subjetivo latino-americano do período. Além da maior disseminação das tecnologias digitais, com câmeras mais leves e menores, em geral acopladas a gravadores, ele lista como fatores fundamentais o "cansaço com os filmes de entrevistas sobre as ditaduras" e "o enfraquecimento de discursos totalizantes que, ao passo das políticas neoliberais e do enfraquecimento do estado, dão lugar a narrativas subjetivas" (PIEDRAS, 2016, p. 82) ${ }^{9}$. O giro subjetivo se associa ainda à

\footnotetext{
${ }^{8}$ Consuelo Lins observa, no mesmo sentindo, que "Nos filmes de Coutinho, os moradores da favela não estão condenados a nada. Encontram-se evidentemente inseridos em um contexto histórico, sofrem de males comuns, possuem um perfil sociológico, mas de maneira nenhuma se reduzem a ele. A vida de quem mora na favela é efetivamente dura e está sujeita a diferentes poderes e violências, mas é assim de diferentes formas, e é também uma infinidade de outras coisas. Ambigüidades e sentidos múltiplos não são "resolvidos" na montagem; as contradições não ganham uma síntese, mas são postas lado a lado" (LINS, 2004, p. 72).

9 A sucessão desse parágrafo ao anterior pode gerar o entendimento de que reagia-se aos filmes de Eduardo Coutinho. Não é esse o caso. Em sua cinematografia, não há filmes dedicados a ouvir a história de exilados políticos e outras vítimas das ditaduras. Ademais, depois de Cabra marcado para morrer, seus filmes de entrevista tornam-se referência e reconhecidos sobretudo a partir da virada do século quando
} 
mobilidade: os filmes ultrapassam as fronteiras territoriais e fazem uso de múltiplos deslocamentos para questionar as bases da identidade (pessoal, política e cultural). Dentro destes giros, nota-se um importante agenciamento de protagonistas femininas que narram histórias pessoais e fatos históricos e que, frequentemente, exploram

como os pais influenciaram o destino de seus filhos, mostrando-lhes pouco afeto ou deixando lacunas na história da família. Na tentativa de mitigar essas dívidas, os filmes funcionam como atos de reparação sócioestética em que as filhas contam suas histórias de forma reflexiva, de modo que as empodere a questionar os fatos. Não é por acaso, então, que os filmes contêm diálogos pai-filha que perturbam as relações de poder assimétricas e intervêm na história pública (normalmente o domínio dos homens) usando sensibilidades tradicionalmente atribuídas à esfera doméstica "feminina". (PIEDRAS, 2016, p. 84)

Entre seus filmes citados, estão Papá Iván, de María Inés Roqué (2004), Diário de uma busca, de Flávia Castro (2010) e Os dias com ele, de Maria Clara Escobar (2012). Poderíamos acrescentar outros documentários subjetivos femininos que fogem dessa relação parental, como Passaporte Húngaro, de Sandra Kogut (2001) ${ }^{10}$.

Contrariando a ideia de que o documentário em primeira pessoal é um simples exercício de narcisismo ou uma versão contemporânea dos filmes burgueses autorais, María Guadalupe Arenillas e Michael J. Lazzara afirmam que, embora tais aspectos não estejam de todo ausentes, trata-se de algo mais profundo, não apenas porque "A diretora [o diretor], como sujeito de primeira pessoa, vai em busca do outro para aprender algo, mas também para aprender algo sobre si mesma [mesmo], ou talvez ainda mais importante sobre a relação entre si e o outro" (ARENILLAS; LAZZARA, 2016, p. 6-7), mas também porque

realiza em sequência Santo Forte (1999), Babilônia 2000 (2000), Edifício Master (2002), Peões (2004), O Fim e o Princípio (2005) e, de forma experimental, Jogo de Cena (2007).

${ }^{10}$ Este, ao lado de 33, de Kiko Goifman (2002), são analisados por Jean-Claude Bernardet como exemplos de documentário de busca, filmes "que partem de um alvo bastante preciso, bastante determinado, mas os cineastas não sabem se esse alvo será ou não atingido e não sabem de que forma será atingido. Portanto, a filmagem tende a se tornar a documentação do processo" (BERNARDET, 2005, p. 144). No caso do filme de Sandra Kogut, trata-se de uma busca pelo objeto nomeado no título, que passa por diálogos com a avó materna exilada no Brasil depois de fugir dos nazistas que ocupam a Hungria, por frequentes deslocamentos entre países e por embaixadas, consulados e arquivos públicos. 
Como o "eu" existe em uma relação social com o outro, fica claro que os documentários em primeira pessoa têm tudo a ver com a noção de comunidade, com a criação de regimes de afeto, identificação e conexão em tempos em que reina a desigualdade, em que a exclusão é galopante e as pessoas estão famintas (sic) por relações sociais significativas. Ao dizer "eu", então, o sujeito documental em primeira pessoa torna-se vulnerável, aberto à transformação pelo outro, pronto para afetar a história e ser afetado por ela. (ARENILLAS; LAZZARA, 2016, p.7)

Andrés Di Tella, autor de filmes em primeira pessoa como La televisión y yo (2003) afirma que, para ele, um filme em primeira pessoa será legítimo se "representar uma espécie de coming out do documentarista, como se diz dos homossexuais que se atreveram a assumir sua homossexualidade. Ou seja, não deve ser um gesto gratuito para a pessoa do cineasta: deve implicar algum risco, deve envolver uma adesão a uma atitude que para algum crítico implicante resulta 'temerária”' (DI TELLA, 2005, p. 71). Buscando uma expressão que dê conta da complexidade desse Eu, Alisa Lebow afirma, a partir de Jean Luc Nancy, uma ressonância entre o Eu e o Nós.

Sinto-me cada vez mais persuadida pela formulação de Jean Luc Nancy (2000) do plural singular, em que o indivíduo "eu" não existe sozinho, mas sempre "com" outro, ou seja, ser um nunca é singular, mas sempre implica e, de fato incorpora outro. Isso significa que o "eu" é sempre social, sempre já em relação, e quando fala, como fazem esses cineastas, na primeira pessoa, pode parecer estar na primeira pessoa do singular "eu", mas ontologicamente falando, é sempre, com efeito, a primeira pessoa do plural "nós". A referência gramatical nos lembra que a própria linguagem, embora falada por um indivíduo, nunca é inteiramente invenção nossa, nem de outra pessoa. (LEBOW, 2012, p. 2-3)

\section{Documentários realizados por seus objetos modernos}

O terceiro traço presente em Jardim Nova Bahia a marcar a produção contemporânea é o reordenamento das relações entre realizadores e o "outro social". Ele é particularmente visível na produção das periferias e em projetos de empoderamento

\footnotetext{
${ }^{11}$ Sobre esse aspecto ético do cinema em primeira pessoa, Andrés Di Tella acrescenta: "Colocar no filme uma substância autobiográfica, sacrificar a própria família, expor as intimidades da experiência, tudo isso é uma espécie de oferta pública" (DI TELLA, 2005, p. 71).
} 
social que viabilizam que os até então objetos dos filmes passam a contar suas próprias histórias. Um dos mais emblemáticos é o Vídeo nas Aldeias, projeto de cinema colaborativo iniciado em 1986 com o filme A festa da moça, realizado a partir do encontro de Vincent Carelli com a comunidade Nambikwara no Mato Grosso. Um dos fundadores do projeto, Carelli afirma que começou a filmar os rituais e encontros políticos dos ameríndios com uma câmera recém-adquirida, mas que o filme logo foi apropriado pelos indígenas, que passaram a determinar o que deveria ser filmado e falavam sem se preocupar se estavam sendo entendidos ou não: "na verdade, eles estavam fazendo [o vídeo] para eles", conta Carelli (2015 apud LACERDA, 2008, p. 6). A partir de 1997, o Vídeo nas Aldeias passou a ser um programa formador, que envolve o letramento audiovisual dos participantes. A equipe de formação costuma ser constituída por duas pessoas, sendo cada vez mais frequente que os instrutores tenham sido formados em oficinas anteriores. Um dos mais destacados é Divino Tserewahú, diretor de Wai á Rini: o poder de sonho (2001) que narra a festa Wai’á, cerimônia do povo Xavante na qual o jovem é iniciado na vida espiritual e no contato com forças sobrenaturais.

\section{Documentário ensaístico}

Atualmente, assistimos a uma profícua produção de documentários de caráter ensaístico. Abordando diversos aspectos e dilemas sociais a partir de um recurso maior ou menor à subjetividade autoral, essa forma de fazer cinema gerou alguns dos documentários contemporâneos de maior repercussão na crítica especializada ou não: Santiago - reflexões sobre o material, de João Moreira Salles (2006) e Democracia em Vertigem, de Petra Costa (2018). Apesar de serem conduzidos por narração em primeira pessoal, ancorados na subjetividade de quem os dirige e abordarem a história do país a partir de famílias da elite econômica, os filmes têm pouco em comum: diferem na dimensão dos eventos que registram, no tamanho da produção que realizam e do público que almejam, no arranjo narrativo, em seus objetivos.

Outro exemplo de produção de caráter ensaístico é a mais recente trilogia de um dos mais importantes documentaristas do cinema: o chileno Patricio Guzmán, realizador 
do épico A batalha do Chile (1973-1979) que registra o bombardeamento do Palácio La Moneda e a divisão e as tensões sociais do povo chileno. Guzmán dedicou a maior parte de sua obra a tratar da ditadura chilena e, na última década, abordou suas consequências contemporâneas partindo dos elementos geofísicos mais marcantes do Chile: o deserto do Atacama, o Oceano Pacífico e a Cordilheira dos Andes, respectivamente em Nostalgia da luz (2010), O botão de nácar (2015) e A cordilheira dos sonhos (2019). Essa trilogia parece trazer em si diversos aspectos da produção latino-americana que analisamos desde meados do século 19. Há a denúncia da situação social chilena (o sofrimento social causado pelo neoliberalismo, as feridas abertas deixadas pelo período ditatorial), entrevistas que dedicam-se à coleta de histórias frágeis (mas também a reflexões mais amplas), a partilha das imagens do filme com Pablo Salas (que filmou a repressão visível de Pinochet durante a ditadura), tudo isso ancorado na subjetividade de Guzmán, narrador em primeira pessoa do filme, que intercala nesta narração sua experiência pessoal com aspectos cosmológicos e históricos.

\section{Conclusão}

O passado leva consigo um índice secreto pelo qual ele é remetido à redenção. Não nos afaga, pois, levemente um sopro de ar que envolveu os que nos precederam? [...] se assim é, um encontro secreto está então marcado entre as gerações passadas e a nossa. Então fomos esperados sobre a terra. Então nos foi dada, assim como a cada geração que nos precedeu, uma fraca força messiânica, à qual o passado tem pretensão. (BENJAMIN, 2005, p. 48)

Mais do que apontar as perspectivas e desafios futuros do cinema documentário latino-americano, gostaria de apontar algumas perspectivas e desafios passados. Não é para menos: as preocupações sociais e os recursos estéticos e narrativos que marcam essa forma de fazer filmes na América Latina foram tratados com tamanha habilidade, dedicação e vivacidade que, mesmo em um conjunto de filmes consideravelmente menor do que aquele dos países do Norte, destacam-se como precursores desde as primeiras décadas do século XX. A rigor, se o cinema documentário se institucionaliza e passa a ser 
reconhecido como tal apenas nos anos 1920, o documentário latino-americano busca traduzir os dilemas sociais do continente desde antes de sua invenção.

Já na década de 1910, os cineastas que deixaram as cidades metropolitanas em direção ao interior mexicano, onde ocorriam os conflitos armados da Revolução, realizavam obras inovadoras que se distinguiam dos cine-jornais meramente informativos: não apenas registravam os eventos e conflitos, mas os distintos pontos de vista sobre ele. Zuzana Pick destaca que os filmes dos Irmãos Alva e de Jesús H. Abatía demonstram, por suas propriedades estéticas e narrativas, uma complexa compreensão do "potencial historicizante do cinema ao registrar os diferentes aspectos e experiências da revolução" (PICK, 2010, p. 25). Na mesma década, mas no extremo sul do continente, o antropólogo Alcides Greca realiza El último malón (1917), filme que reconstitui a revolta ameríndia ocorrida na cidade argentina de San Javier alguns anos antes ${ }^{12}$ tendo como a população local e por locações, o espaço em que de fato os eventos haviam ocorrido. Eses aspectos de El último malón são essenciais para Nanook, o esquimó (Robert Flaherty, 1922) filme comumente considerado o primeiro documentário.

Redes, filme de Emilio Gómez Muriel e Fred Zinnemann, realizado em 1936, que, assim como a obra de Greca, também encena uma história retirada da própria comunidade (a luta dos pescadores do Golfo do Mexicano contra a exploração laboral) ${ }^{13}$ em locações autênticas e com atores sociais. Mas não é apenas isso: Redes é um precursor "do que mais tarde se tornará uma grande tendência do cinema politicamente comprometido em todos os cantos da América Latina" e, mais do que isso, "um

\footnotetext{
${ }^{12}$ Depois de serem massacrados em 1884 por uma campanha militar no Gran Chaco, os mocoví migram para San Javier. Desnutridos e distante de suas caças, são explorados em empregos degradantes, subindo à miséria, ao alcoolismo, à tuberculose, à lepra e às enfermidades venéreas em decorrência de estupros e prostituição (TOMPKINS, 2014, p. 104)

${ }^{13}$ Marcado por diversos conflitos de produção entre os entes envolvidos e mesmo com a população local, "Para alguns, a chegada de uma equipe cinematográfica era a oportunidade para conseguir um dinheiro extra, o que dificultou a compra de barcos e redes, material necessário para as filmagens e oferecido a um preço alto à equipe. Além disso, a falta de experiência dos atores amadores que participaram das filmagens muitas vezes causou problemas sérios para a produção, como o caso do pescador Felipe Rojas, que interpreta o personagem Mingo. Durante as filmagens, Rojas começou a insistir que seu personagem deveria ser o herói da história. Apesar de Strand explicar para o pescador que isso seria impossível, já que seu personagem era o capataz de Dom Anselmo, Rojas raspou sua barba em protesto. Como Mingo é um personagem importante no filme, para evitar erros de continuidade, a equipe teve que esperar um mês até continuar as filmagens das cenas em que Rojas aparecia" (MARTINS, 2018, p. 57).
} 
extraordinário neorrealismo avant la lettre" que leva o espectador a imaginar "um cinema diferente que poderia ter existido, onde a simples oposição entre ficção e documentário é transcendida" (CHANAN, 2013, p. 525).

Parte de um conjunto de filmes extremamente pequeno que vem se tornando progressivamente menor se observarmos as condições de conservação e preservação das obras latino-americanas e os não raros incêndios, enchentes e deteriorações que apagam e incineram essas e outras artes latino-americanas.

Em 2021, um incêndio atingiu um dos galpões da Cinemateca Brasileira. Como observam Adirley Queirós, Affonso Uchoa, Cristina Amaral, Eryk Rocha, Ewerton Belico, Luiz Pretti e Thiago B. Mendonça, não se trata de um acidente:

Os responsáveis sabiam o que faziam e mesmo assim o fizeram. Foram seguidamente avisados da gravidade da situação e escolheram colocar em risco um patrimônio coletivo que se perdeu. Outros materiais seguem em perigo. Perigo de destruição imediata, em um novo incêndio. Perigo da destruição silenciosa, de filmes que apodrecem dentro de latas sem o devido cuidado (AMARAL et al, 2021, s/p) ${ }^{14}$.

O documentário El misterio de los ojos escarlata (1993), realizado pelo venezuelano Alfredo Anzola com imagens desconhecidas filmadas por seu pai entre as décadas de 1920 e 1940, recupera e exibe imagens inteiramente desconhecidas do passado venezuelano. O filme foi valorizado por um de seus espectadores por possuir "uma dimensão pedagógica muito valiosa. Abre-nos os olhos a um país não apenas esquecido e desconhecido, mas também bloqueado pelos preconceitos que nos impedem de vê-lo em sua realidade e processo nus" (SOSA, 1993, p. 182). A partir dele, podemos nos perguntar, com Michael Chanan:

\footnotetext{
${ }^{14}$ Em The Taking of the Cinemateca Brasileira (2021), Darlente Sadlier faz uma análise irretocável das condições de trabalho e conservação da Cinemateca Brasileira, assim como um retrospecto das perdas do Cinemateca Brasileira ao longo da história, que incluem as enchentes de fevereiro de 2020 quando mais de cem mil DVD's foram inutilizados e outro incêndio, ocorrido em 1957, que consumiu livros, gravações, câmeras e praticamente a totalidade da coleção de cópias de filmes utilizadas em cineclubes.
} 
Quantos outros cineastas latino-americanos quase anônimos dos primeiros anos tiveram carreiras semelhantes? Será que eles deixaram arquivos desconhecidos? Quantos desses aficionados nem sequer deixaram seus nomes para trás? (CHANAN, 2013, p. 526)

Mais do que nos perguntarmos, devemos buscar a interrupção desses desaparecimentos. Além do engajamento em esferas comunitárias, sociais e políticas, devemos como pesquisadores(as) e documentaristas nos apropriar dessas obras frágeis, como as palavras de quem não costuma ser ouvido, com desvelo e um senso de urgência, impedindo que elas desapareçam ou que, por serem conhecidas, ao desaparecerem não desapareçam por completo - inventando sua permanência.

\section{Referências}

ÁLVAREZ, Santiago. Arte y compromisso. In: LEDUC, Paul; LÓPEZ, José; SÁNCHEZ, Jorge (orgs.). Hojas de cine: testimonios y documentos del nuevo cine latinoamericano:

volumen III. Cidade Do México: Ed. Universidad Autónoma Metropolitana, 1988. p. 29-31.

AMARAL, Cristina; BELICO, Ewerton; MENDONÇA, Thiago B.; PRETTI, Luiz; QUEIRÓS, Adirley; ROCHA, Eryk; UCHOA, Affonso. Cinemateca, entre o deserto e a miragem. Le monde diplomatique Brasil, São Paulo, 19 de agosto. Disponível em:

https://diplomatique.org.br/cinemateca-entre-o-deserto-e-a-miragem/. Acesso em: 11 nov. 2021.

ARENILLAS, María Guadalupe; LAZZARA, Michael J. (orgs.). Latin American Documentary Film in the New Millennium. New York: Palgrave Macmillan, 2016.

AUTRAN, Arthur. O pensamento industrial cinematográfico brasileiro. São Paulo: Hucited Editora, 2013.

AVELLAR, José Carlos. A ponte clandestina. São Paulo: Edusp, 1995.

BALTAR, Marina. Realidade lacrimosa: diálogos entre o universo do documentário e a imaginação melodramática. 2007. Tese (Doutorado em Comunicação) - UFF, Niterói, 2007.

BENJAMIN, Walter. Sobre o conceito de história. In: LÖWY, Michael. Walter Benjamin: aviso de incêndio: uma leitura das teses "sobre o conceito de história". Tradução Wanda 
Nogueira Caldeira Brant. Tradução das teses: Jeanne Marie Gagnebin, Marcos Lutz Müller. São Paulo: Boitempo, 2005.

BERNARDET, Jean-Claude. Cineastas e imagens do povo. São Paulo: Companhia das Letras, 2003.

BERNARDET, Jean-Claude. Documentários de busca: 33 e Passaporte Húngaro. In: LABAKI, Amir \& MOURÃO, Maria Dora (orgs.). O cinema do real. São Paulo: Cosac Naify, 2005. p. 142-157.

BIRRI, Fernando. Cine y subdesarrollo. In: LEDUC, Paul; LÓPEZ, José; SÁNCHEZ, Jorge (orgs.) Hojas de cine: testimonios y documentos del nuevo cine latinoamericano: volumen II. Cidade Do México: Ed. Universidad Autónoma Metropolitana, 1988. p. 12-17.

BIRRI, Fernando. Para seguir resistiendo. In: LEDUC, Paul; LÓPEZ, José; SÁNCHEZ, Jorge (orgs.) Hojas de cine: testimonios y documentos del nuevo cine latinoamericano: volumen I. Cidade Do México: Ed. Universidad Autónoma Metropolitana, 1988. p. 71-75.

CABRERA, Marta. Audiovisual Affect: sexuality and the public sphere in the work of Colombia's Escuela Audiovisual al Borde. In: ARENILLAS, María Guadalupe; LAZZARA, Michael J. (orgs.). Latin American Documentary Film in the New Millennium. New York: Palgrave Macmillan, 2016. p. 191-206.

CÂNDIDO, Antônio. A educação pela noite e outros ensaios. São Paulo: Atica, 1989.

CHANAN, Michael. Latin America. In.: AITKEN, lan (org.). The Concise Routledge Encyclopedia of the Documentary Film. New York: Routledge, 2013. p. 524-531.

COMOLLI, Jean-Louis. Ver e poder: a inocência perdida: cinema, televisão, ficção, documentário. Tradução Augustin de Tugny, Oswaldo Teixeira e Ruben Caixeta. Belo Horizonte: Editora UFMG, 2008.

COUTINHO, Eduardo; XAVIER, Ismail; FURTADO, Jorge. O sujeito (extra)ordinário. In: LABAKI, Amir; MOURÃO, Maria Dora (orgs.). O cinema do real. São Paulo: Cosac Naify, 2005. p. 96-141.

DA-RIN, Silvio. Espelho partido. Rio de Janeiro: Azougue Editorial, 2006.

DI TELLA, Andrés. O documentário e eu. Tradução de Andrea Molfeta. In: Mourão, Maria Dora; Labaki, Amir (orgs.). $O$ cinema do real. São Paulo: Cosac Naify, 2005. p. 68-81.

DUGUET, Anne-Marie. Dispositivos. In: MACIEL, Kátia. Transcinemas. São Paulo: Contracapa, 2009. p. 49-70. 
ESPINOSA, Julio García. Respuesta de Julio García Espinosa a la revista chilena de cine Primer Plano. In: LEDUC, Paul; LÓPEZ, José; SÁNCHEZ, Jorge (orgs.). Hojas de cine: testimonios y documentos del nuevo cine latinoamericano: volumen III. Cidade Do México: Ed. Universidad Autónoma Metropolitana, 1988. p. 67-71.

GETINO, Octavio; SOLANAS, Fernando. Hacia un tercer cine. In: LEDUC, Paul; LÓPEZ, José; SÁNCHEZ, Jorge (orgs.). Hojas de cine: testimonios y documentos del nuevo cine latinoamericano: volumen I. Cidade Do México: Ed. Universidad Autónoma Metropolitana, 1988. p. 23-50.

GRIERSON, John. Flaherty's poetic Moana. In: JACOBS, Lewis. The documentary tradition. New York: W. W. Norton \& Company, 1979. p. 25-26.

JACOBS, Lewis. The documentary tradition. New York: W. W. Norton \& Company, 1979.

LACERDA, Rodrigo. O cinema indígena colaborativo do Vídeo nas Aldeias e o Património Cultural Imaterial. Memoriamedia, Lisboa, v. 3, p. 1-11, 2018.

LEBOW, Alisa (org.). The Cinema of me: the Self and subjectivity in first person documentary. London: Wallflower press, 2012.

LINS, Consuelo. O documentário de Eduardo Coutinho: televisão, cinema e vídeo. Rio de Janeiro: Jorge Zahar Ed., 2004.

LINS, Consuelo. Rua de Mão Dupla: documentário e arte contemporânea. Rio de Janeiro, 2012. Disponível em http://www.caoguimaraes.com/wordpress/wp-

content/uploads/2012/12/rua-de-mao-dupla-documentario-e-arte-contemporanea.pdf

LINS, Consuelo; MESQUITA, Cláudia. Filmar o real: sobre o documentário brasileiro contemporâneo. Rio de Janeiro: Jorge Zahar, 2008.

MARTINS, Anderson Montagner. O projeto cinematográfico da Secretaría de Educación Pública do México: tensões e ambiguidades em torno do filme Redes (1934-1936). 2018. Dissertação (Mestrado em História) - Faculdade de Ciências e Letras, Universidade Estadual Paulista, Assis, 2018.

MATTOS, Tetê. A imaginação cinematográfica em Di-Glauber. In: TEIXEIRA, Francisco Elinaldo (org.) Documentário no Brasil: tradição e transformação. São Paulo: Summus, 2004. p. 157-178.

PARANAGUÁ, Pablo. América Latina Busca su imagen. In: HEREDERO, Carlos F. E TORREIRO, Casimiro (orgs.). História general del cine volume X. Madri: Cátedra, 1996. p. 207-384. 
PICK, Zuzana M. Constructing the image of the Mexican revolution: cinema and the archive. Austin: University of Texas Press, 2010.

PIEDRAS, Pablo. The "Mobility Turn" in Contemporary Latin American First-Person Documentary. In: ARENILLAS, María Guadalupe; LAZZARA, Michael J. (orgs.). Latin American documentary film in the new millennium. New York: Palgrave Macmillan, 2016. p. 79-.96.

RAMOS, Fernão Pessoa. Mas afinal... o que é mesmo documentário? São Paulo: Editora Senac, 2008.

ROCHA, Glauber. A revolução do cinema novo. São Paulo: Cosac Naify, 2004.

SADLIER, Darlene J. The taking of the cinemateca brasileira. Black Camera 12, Bloomington, n. 2, p. 591-608, 2021. Disponível em:

https://doi.org/10.2979/blackcamera.12.2.27. Acesso em: 11 nov. 2021.

SANJÍNES, Jorge. Testimonio en Mérida. In: LEDUC, Paul; LÓPEZ, José; SÁNCHEZ, Jorge (orgs.) Hojas de cine: testimonios y documentos del nuevo cine latinoamericano: volumen I. Cidade Do México: Ed. Universidad Autónoma Metropolitana, 1988. p. 76-79.

SANJÍNES, Jorge; BESKOW, Cristina Alvares. Un cine de combate junto al pueblo. Entrevista con el cineasta boliviano Jorge Sanjinés. Cinema Comparative Cinema, Barcelona, n. 9, p. 22-30, 2016.

SALLES, João Moreira. Prefácio. In: LINS, Consuelo. 0 documentário de Eduardo Coutinho: televisão, cinema e vídeo. Rio de Janeiro: Jorge Zahar, 2004.

SCHVARZMAN, Sheila. Humberto Mauro e o documentário. In: TEIXEIRA, Francisco Elinaldo (org.). Documentário no Brasil: tradição e transformação. São Paulo: Summus, 2004. p. 261-296.

SHERWOOD, Robert. Robert Flaherty's Nanook of the North. In: JACOBS, Lewis. The documentary tradition. New York: W. W. Norton \& Company, 1979. p. 15-19.

SOSA, Arturo. El misterio de los ojos escarlata. Revista SIC, Caracas, v. 56, n. 554, p. 181$183,1993$.

TACCA, Fernando de. Luiz Thomaz Reis: etnografias fílmicas estratégias. In: TEIXEIRA, Francisco Elinaldo (org.). Documentário no Brasil: tradição e transformação. São Paulo: Summus, 2004. p. 313-370. 
THORNTON, Niamh. Revolution and rebellion in Mexican. Londres: Bloomsbury Academic, 2013.

TOMPKINS, Cynthia. El último malón (1916) de Alcides Greca: repetición y cine de atracciones. Studies in Latin American Popular Culture, Austin, n. 32, p. 97-119, jun. 2014.

Recebido em: 28/02/2021

Aprovado em: 25/11/2021

Universidade do Estado de Santa Catarina - UDESC Centro de Ciências Humanas e da Educação - FAED

PerCursos

Volume 22 - Número 50 - Ano 2021 revistapercursos@gmail.com 